(n)

\title{
Androgens are bronchoactive drugs that act by relaxing airway smooth muscle and preventing bronchospasm
}

\author{
Luis M Montaño², Julia Espinoza', Edgar Flores-Soto ${ }^{2}$, Jaime Chávez ${ }^{3}$ and \\ Mercedes Perusquía' \\ ${ }^{1}$ Departamento de Biología Celular y Fisiología, Instituto de Investigaciones Biomédicas and \\ ${ }^{2}$ Departamento de Farmacología, Facultad de Medicina, Universidad Nacional Autónoma de México, \\ Mexico, Distrito Federal 04510, Mexico \\ ${ }^{3}$ Departamento de Investigación en Hiperreactividad Bronquial, Instituto Nacional de Enfermedades \\ Respiratorias Ismael Cosio Villegas, Mexico, Distrito Federal, Mexico
}

Correspondence should be addressed to M Perusquía

Email

perusqui@unam.mx

\begin{abstract}
Changes in the androgen levels in asthmatic men may be associated with the severity of asthma. Androgens induce a nongenomic relaxation in airway smooth muscle, but the underlying mechanisms remain unclear. The aim of this study was to investigate the potential bronchorelaxing action of testosterone (TES) and its metabolites ( $5 \alpha$ - and $5 \beta$-dihydrotestosterone (DHT). A preventive effect on ovalbumin (OVA)-induced bronchospasm was observed in sensitized guinea pigs for each androgen. Androgens were studied in response to bronchoconstrictors: carbachol (CCh) and $\mathrm{KCl}$ in isolated trachea rings with and without epithelium from non-sensitized and sensitized animals as well as on OVA-induced contraction. Androgens concentration-dependently abolished the contraction in response to $\mathrm{CCh}, \mathrm{KCl}$, and OVA. There were significant differences in the sensitivity to the relaxation induced by each androgen. $5 \beta$-DHT was more potent for relaxing $\mathrm{KCl}$-induced contraction, while TES and $5 \alpha-\mathrm{DHT}$ were more potent for CCh- and OVA-induced contraction. No differences were found in preparations with and without epithelium or in the presence of a nitric oxide (NO) synthase inhibitor or an inhibitor of $\mathrm{K}^{+}$channels. These data indicate the absence of involvement of the epithelium-, NO- and $\mathrm{K}^{+}$channels-dependent pathway in androgen-induced relaxation. However, in dissociated tracheal myocytes loaded with the calcium-binding fluorescent dye Fura -2 , physiological concentrations of androgens decreased the $\mathrm{KCl}$-induced $\left[\mathrm{Ca}^{2+}\right]_{\mathrm{i}}$ increment. $5 \beta$-DHT was the most potent at decreasing $\mathrm{KCl}$-induced $\left[\mathrm{Ca}^{2+}\right]_{i}$ increment and preventing bronchospasm. We suggest that androgen-induced brochorelaxation was mediated via decreased $\mathrm{Ca}^{2+}$ influx through L-type $\mathrm{Ca}^{2+}$ channels but additional $\mathrm{Ca}^{2+}$ entry blockade may be involved. Molecular changes in androgen structure may determine its preferential site of action.
\end{abstract}
Key Words
- asthma
- testosterone
- $5 \alpha$-dihydrotestosterone
- $5 \beta$-dihydrotestosterone
- bronchoactive steroids
- airway smooth muscle

Journal of Endocrinology (2014) 222, 1-13

\section{Introduction}

It is well know that asthma is a chronic disease that affects the airways and is responsible for substantial worldwide morbidity and mortality. An association between asthma and sex steroid hormones has been noticed. Clinical and epidemiological studies agree that before puberty, childhood asthma is more frequent in boys than in girls (Bonner 1984, Ninan \& Russell 1992, Sears 1997, Zannolli \& Morgese 1997, http://joe.endocrinology-journals.org DOI: 10.1530/JOE-14-0074
() 2014 Society for Endocrinology Printed in Great Britain
Published by Bioscientifica Ltd 
The International Study of Asthma and Allergies in Childhood 1998, Becklake \& Kauffmann 1999, Mutius \& Martínez 1999, Kjellman \& Gustafsson 2000, Osman 2003, Townsend et al. 2012), but following puberty, asthma is more prevalent among adult women and women exhibit a more severe form compared with men (Paoletti et al. 1995, Becklake \& Kauffmann 1999, de Marco et al. 2000, Osman 2003, Melgert et al. 2007, Postma 2007, Almqvist et al. 2008, Chen et al. 2008, Jeon et al. 2009). Remarkably, asthma severity decreases during adolescence only among males. Likewise, it has been documented that the low testosterone (TES) levels in elderly men may exacerbate asthma, but additional studies are needed to determine the role, if any, of low TES levels in the risk of asthma. Nevertheless, taken together, these lines of evidence indicate that the difference in the disease may be associated with the sex hormones.

In general, it is accepted that female sex hormones (estrogens and progesterone) aggravate asthma and other allergic diseases, whereas male sex hormones (androgens) suppress such illness (Haggerty et al. 2003, Osman 2003, Townsend et al. 2012, Ticconi et al. 2013). Consequently, the available data indicate that androgens, indeed, play a major role in asthma, which might be associated with low TES level in childhood or deficiency in the aging male.

Steroid hormones elicit very rapid effects that are not mediated by the classic intracellular steroid receptors (nongenomic mechanism). This effect of steroids on airway smooth muscle (ASM) has been scantily examined. We have previously demonstrated that progesterone and its immediate $5 \beta$-reduced metabolite, pregnanolone, induce a nongenomic relaxation of guinea pig trachea (Perusquía et al. 1997). Likewise, estrogens have also been reported to be nongenomic relaxants (Townsend et al. 2010, 2012). Little attention has also been paid to the effect of androgens on ASM, only three basic research studies have examined this issue. Using male rabbit tracheal strips, it was found that TES and TES-BSA induce a slight relaxation on the acetylcholine-induced contraction which seems to be partially mediated through epithelium and nitric oxide (NO; Kouloumenta et al. 2006). Similarly, in male guinea pig and bovine tracheal rings and strips, the $5 \alpha$-reduced metabolite of TES, $5 \alpha$-dihydrotestosterone ( $5 \alpha$-DHT), produces substantial nongenomic relaxation on carbachol (CCh)- and $\mathrm{KCl}-$ induced contraction (Bordallo et al. 2008); these relaxations are epithelium independent, contrasting with the study of Kouloumenta et al. (2006). In addition, Bordallo et al. (2008) also found the first clue that the relaxant effect elicited by $5 \alpha$-DHT might be attributed to voltage-gated L-type $\mathrm{Ca}^{2+}$ channel blockade. Indeed, the findings of these two pioneer studies have revealed that androgeninduced relaxation on ASM is nongenomically mediated, but the role of epithelium is yet unclear, and the limited in vitro data do not provide any solid indication about the site of the relaxing action of androgens. Recently, our group has provided evidence that the precursor of these androgens, DHEA, is also capable of inducing a nongenomic epithelium-independent relaxation of the ASM of male guinea pigs. DHEA also prevents the bronchospasm induced by ovalbumin (OVA) in sensitized guinea pigs; an effect produced directly by DHEA and not after its bioconversion into TES or estrogens. Moreover, our data indicated that DHEA-induced ASM relaxation may involve, at least in part, a blockade of voltage-dependent $\mathrm{Ca}^{2+}$ channels (Espinoza et al. 2013).

Contraction of ASM is considered to be an important pathway leading to the manifestation of asthmatic symptoms. Obviously, the role of androgens in the regulation of airway contractile action, by inducing relaxation, is of considerable importance and merits continued investigation. In this context, our study was designed to explore the direct action of TES and its 5-reduced metabolites on a guinea pig model of allergic asthma. The preventive effect of TES, $5 \alpha$-DHT or $5 \beta$-DHT, on the bronchospasm induced by OVA in guinea pigs was examined using anesthetized whole-body plethysmography. Of particular interest was comparison of the in vitro relaxation effects of androgens on the $\mathrm{KCl}-$, CCh-, or OVA-induced tracheal smooth muscle contraction in non-sensitized and sensitized guinea pigs. In addition, we also studied the role of i) epithelium, under controlled conditions that ensured the removal of epithelium and ii) $\mathrm{K}^{+}$channels in the androgen-induced relaxation of ASM. Likewise, in order to shed further light on the mechanism of action of androgen-caused relaxation, additional experiments were carried out using single ASM cells to examine whether androgens may affect $\mathrm{KCl}$-induced intracellular $\mathrm{Ca}^{2+}$ increment.

\section{Materials and methods}

\section{Animals}

Adult male guinea pigs of the Hartley strain (450-600 g) at 89 weeks of age were obtained from the animal facility from the Instituto Nacional de Enfermedades Respiratorias, Ismael Cosio Villegas (Mexico City). The animals were housed under conventional conditions (filtered conditioned air, $21 \pm 1{ }^{\circ} \mathrm{C}$, $50-70 \%$ humidity, sterilized bed) and supplied with Purified

Published by Bioscientifica Ltd. 
Guinea Pig Diet pellets (Harlan, Inc., Mexico City, Mexico) and water and allowed to eat and drink ad libitum. The protocols were approved by the Institutional Care and Use Committee of the Instituto de Investigaciones Biomédicas, Universidad Nacional Autónoma de México. The experiments were conducted in accordance with the published Guiding Principles for Care and Use of Vertebrate Animals in Research and Training, approved by the American Physiological Society. The guinea pigs were grouped into nonsensitized (healthy, unchallenged control animals) or sensitized (animal model of allergic asthma, OVA-sensitized/challenged animals) groups.

\section{OVA-sensitization procedure}

To obtain the animal model of allergic asthma, guinea pigs were sensitized at day 1 by administration of $0.5 \mathrm{ml}$ i.p. and $0.5 \mathrm{ml}$ s.c. $60 \mu \mathrm{g} / \mathrm{ml}$ OVA and $1 \mathrm{mg} / \mathrm{ml} \mathrm{Al}(\mathrm{OH})_{3}$ (as adjuvant) dissolved in saline $(0.9 \% \mathrm{NaCl})$. At day 8 , the animals received an antigenic challenge with $3 \mathrm{mg} / \mathrm{ml}$ OVA in saline solution nebulized during $5 \mathrm{~min}$, delivered by an ultrasonic nebulizer (WH-2000; Medical Instrument Factory Co. Ltd, Guangdong, China). On day 15, animals received another antigenic challenge with $1 \mathrm{mg} / \mathrm{ml}$ OVA in saline solution nebulized for $1 \mathrm{~min}$. The response to antigen was always established by deep abdominal breathing. Thus, only guinea pigs with increased dyspnea were selected for this study. Finally, the guinea pigs were subjected to experimentation at days 21-25.

\section{Androgen effect on OVA-induced bronchospasm}

Lung resistance $\left(\mathrm{R}_{\mathrm{L}}\right)$ was measured by using the isovolumetric method in a closed-chamber plethysmograph (Buxco Electronics, Inc., Wilmington, NC, USA). Sensitized guinea pigs (after 21-25 days) were anesthetized with sodium pentobarbital (35 mg/kg, i.p.), and the depth of anaesthesia was maintained with hourly administration of additional doses of pentobarbital as needed. Each animal received pancuronium bromide $(0.06 \mathrm{mg} / \mathrm{kg}$, i.v.) to avoid spontaneous respiratory movements. After cannulating the trachea, each animal was mechanically ventilated through a rodent ventilator (7025; Ugo Basile Biological Research Apparatus, Varese, Italy), with a tidal volume of $10 \mathrm{ml} / \mathrm{kg}$ and 48 breaths/min. The right jugular vein and left carotid artery were cannulated for drug administration (androgen or OVA) and for arterial pressure recording through a dynograph (BPA 400A; Digi-Med Blood Pressure Analyzer, Lousville, KY, USA) respectively. A water-filled cannula was positioned into the middle third of the oesophagus in order to measure the intraoesophageal pressure as a surrogate for intrapleural pressure. Pressures obtained from the oesophageal and tracheal cannulas were recorded through a differential pressure transducer (TRD4510; Buxco Biosystem, Buxco, Wilmington, NC, USA). Pressure inside the plethysmograph chamber was also recorded through another differential pressure transducer. This last signal was converted to a pseudo-flow signal through a software (XA v2.1; Buxco Biosystem), which calculated the relationship between signals from transducers to obtain $\mathrm{R}_{\mathrm{L}}$ through the formula: $\mathrm{R}_{\mathrm{L}}=\Delta P / \Delta V^{\prime}$, where $\Delta P$ is the pressure change and $\Delta V^{\prime}$ is the flow change. The $\mathrm{R}_{\mathrm{L}}$ of the animals was recorded for $3 \mathrm{~min}$ (basal $R_{L}$ value). After $15 \mathrm{~min}$, the guinea pigs received $75 \mu \mathrm{g} / \mathrm{kg}$ per min OVA i.v. administrated in $40 \mu \mathrm{l}$ saline solution, and the $\mathrm{R}_{\mathrm{L}}$ was recorded for $30 \mathrm{~min}$ (control response). To determine whether the bronchospasm produced by OVA could be prevented by the androgens, some animals were pretreated, 15 min before the antigen challenge, with non-cumulative bolus injection of each androgen (TES, $5 \alpha$-DHT or $5 \beta$-DHT) at different i.v. independent doses $(35,110$, or $350 \mu \mathrm{mol} / \mathrm{kg}$ per min) administrated in $40 \mu \mathrm{l}$ dimethylsufoxide (DMSO; $11 \mu \mathrm{mol} / \mathrm{kg}$ per min). $\mathrm{R}_{\mathrm{L}}$ after the antigen challenge was compared in the absence (control response) and presence of androgen administration at different doses or in the pretreatment with the i.v. bolus injection of the same dose-volume of DMSO. The values for $\mathrm{ED}_{50}$ (androgen dose to prevent $50 \%$ of bronchospasm) and $E_{\max }$ (maximal prevention of bronchospasm by androgen) were obtained from the dose-response curves. Only one dose was administrated to each animal. Guinea pigs with a poor response to antigen were discarded from the study.

\section{Tracheal rings preparation and contractile force measurements in vitro}

In order to compare the effect of androgens on healthy (control group) and treated (sensitized group) guinea pigs, we used the same experimental protocol for the two groups. Guinea pigs were deeply anaesthetized with sodium pentobarbital (35 mg/kg, i.p.) and then killed by exsanguination. The trachea was immediately placed in KrebsHenseleit bicarbonate solution (KHS) with the following composition (mM): $\mathrm{NaHCO}_{3}(25), \mathrm{NaCl}$ (120), $\mathrm{KCl}$ (4.7), $\mathrm{KH}_{2} \mathrm{PO}_{4}$ (1.2), $\mathrm{MgSO}_{4}$ (1.2), $\mathrm{CaCl}_{2}$ (2.5), and glucose (11.0); aerated continuously with a gas mixture of $95 \% \mathrm{O}_{2}$ and $5 \%$ $\mathrm{CO}_{2}$ to maintain $\mathrm{pH} 7.4$ and the temperature set at $37^{\circ} \mathrm{C}$. The trachea was cut into eight tracheal rings of $\sim 0.3 \mathrm{~cm}$ of length (each one containing three cartilaginous rings).

To determine the role of the epithelium in the relaxing effect induced by each androgen, tracheal rings

Published by Bioscientifica Ltd. 
from non-sensitized and sensitized animals were used in two ways: i) preparations with epithelium, tracheas were carefully handled to avoid injuring the epithelium and ii) preparations without epithelium which were produced by vigorously rubbing the luminal surface of tracheal rings using a dental drill bur with cylinder round end (K-File Colorinox 140 (Dentsply, York, PA, USA)). The presence and absence of epithelium were evaluated functionally in all experiments. Briefly, each tracheal ring was suspended horizontally between two stainless steel wires, and placed in an organ bath containing $10 \mathrm{ml}$ KHS continuously supplied with $\mathrm{O}_{2}: \mathrm{CO}_{2}$ 95:5 throughout the experiment for recording isometric tension. One wire was attached to a fixed support at the bottom of the chamber and the other end to an isometric force transducer (FTO3C; Grass Instrument, Quincy, MA, USA) connected to a computerized data acquisition and analysis system (MP 150; Biopac Systems, Santa Barbara, CA, USA). The resting force was adjusted to $10 \mathrm{mN}(1 \mathrm{~g})$. Under these conditions, the tissues were equilibrated for $1 \mathrm{~h}$ before the experiments were conducted. Then, the contractile responses to $60 \mathrm{mM}$ $\mathrm{KCl}$ were induced after replacing $\mathrm{KHS}$ with an equimolar quantity of $60 \mathrm{mM} \mathrm{KCl}$ and $64.7 \mathrm{mM} \mathrm{NaCl}$. $\mathrm{KCl}$ caused a tonic contraction, which was repeated three times in order to verify the reproducibility of the response and to determine the maximum stable tonic contraction during $15 \mathrm{~min}$. After each $\mathrm{KCl}$ stimulus, the tissues were washed with KHS to re-equilibrate them for $60 \mathrm{~min}$.

The epithelial condition was pharmacologically corroborated as reported previously (Bramley et al. 1990). Bradykinin (BK) induces epithelium-dependent relaxation; on this basis, $320 \mathrm{nM}$ BK was added to each preparation at basal tone. When the response to BK was observed, the tissues were washed with KHS.

\section{Androgen response on pre-contracted ASM}

Tissues were made to contract by the addition of different agents $(\mathrm{KCl}, \mathrm{CCh}$, or OVA); these contractions were stable with constant amplitude for a long time (recorded during more than $2 \mathrm{~h}$ ). After a stable tension was attained ( $\sim 15 \mathrm{~min})$, different concentrations $(9,20,42,91$, and $200 \mu \mathrm{M})$ of TES, $5 \alpha$-DHT or $5 \beta$-DHT, dissolved in absolute ethanol, were added cumulatively with an interval of $15 \mathrm{~min}$ between each addition. Subsequently, the tissues were washed with KHS to allow them to re-equilibrate for $60 \mathrm{~min}$ before inducing the last contraction with $\mathrm{KCl}$ or $\mathrm{CCh}$, and these contractions were recorded over $90 \mathrm{~min}$ (second control response to verify tissue viability). This was not the case for OVA-induced contraction, which never returned to the baseline after washout. The concentrationresponse curves for each androgen were plotted, and the inhibitory concentration 50 ( $\mathrm{IC}_{50}$; androgen concentration that inhibited $50 \%$ of $\mathrm{KCl}-$, CCh-, or OVA-induced contraction) was calculated to compare the potency of each androgen and the sensitivity of each contraction to androgen-induced relaxation. Likewise, the highest percentage of inhibition, i.e. the maximal relaxing effect $\left(E_{\max }\right)$ on KCl-, CCh-, or OVA-induced contraction, was obtained for each androgen to determine their efficacy. In a separate group of experiments, the effect of the vehicle of androgens (ETOH; absolute ethanol) on the different tonic contractions was determined; each concentration added never exceeded $0.1 \% \mathrm{v} / \mathrm{v}$. The cumulative concentration-response curves for each androgen on contractions induced by different agonists were determined independently for tracheal rings from different animals, expressed as mean \pm s.E.M. $(n=6$, where $n=1$ represents one guinea pig). The $\mathrm{IC}_{50}$ and $E_{\max }$ values for each group were compared among them.

\section{The potential role of NO in the relaxing effect of androgens}

The potential role of NO in androgen-induced relaxation was separately explored. Tracheal rings with epithelium from non-sensitized animals were incubated with the NO synthase inhibitor, $N^{\omega}$-nitro-L-arginine methyl ester (L-NAME, $10 \mu \mathrm{M}$ ), for $30 \mathrm{~min}$ before the $\mathrm{KCl}$-induced contraction, afterwards, the relaxation in response to the same cumulative concentrations of each androgen was measured. The relaxing effect of each androgen was observed over $30 \mathrm{~min}$. The concentration-response curve for each androgen as well as their potency and efficacy was compared between tracheal preparations without and with the L-NAME pretreatment.

\section{Possible interaction of androgens with $\mathrm{K}^{+}$channels}

To analyze the possible interaction of androgens with $\mathrm{K}^{+}$ channels, the relaxing effect of androgens was studied in the presence of tetraethylammonium (TEA); an inhibitor of the voltage-dependent $\mathrm{K}^{+}$channels $\left(\mathrm{K}_{\mathrm{v}}\right)$ at low concentrations $(\leq 1 \mathrm{mM})$, and of the large-conductance $\mathrm{Ca}^{2+}$-activated $\mathrm{K}^{+}$channels $\left(\mathrm{BK}_{\mathrm{Ca}}\right)$ at higher concentrations (10-30 mM) in ASM (Campos-Bedolla et al. 2006). On this basis, three different concentrations of TEA $(1,10$, or $30 \mathrm{mM}$ ) were separately applied $30 \mathrm{~min}$ before the concentration-response curve for each androgen was determined for CCh-induced contraction. The results were compared with the concentration-response curve for each androgen without TEA pretreatment.

Published by Bioscientifica Ltd. 


\section{Measurement of intracellular $\mathrm{Ca}^{2+}$ concentration in guinea pig tracheal myocytes}

Guinea pig tracheal myocytes were obtained as previously reported (Flores-Soto et al. 2013). The cells were loaded with $0.35 \mu \mathrm{M}$ the calcium-binding fluorescent dye Fura-2-AM under low $\mathrm{Ca}^{2+}$ conditions $(0.02 \mathrm{mM})$ at room temperature $\left(22-25^{\circ} \mathrm{C}\right)$. After $1 \mathrm{~h}$, cells were allowed to settle into a $1.5 \mathrm{ml}$ heated perfusion chamber with a glass cover in the bottom. This chamber was mounted on a Nikon inverted microscope (Diaphot 200, Nikon, Tokyo, Japan) and the cells adhered to the glass were continuously perfused at a rate of $2-2.5 \mathrm{ml} / \mathrm{min}$ with KHS containing $2 \mathrm{mM} \mathrm{Ca}^{2+}$ (at $37^{\circ} \mathrm{C}$ and $\mathrm{pH} 7.4$ equilibrated with $5 \% \mathrm{CO}_{2}$ in $\mathrm{O}_{2}$ ). The cells were exposed to alternating pulses of 340 and $380 \mathrm{~nm}$ excitation light, and light emitted at $510 \mathrm{~nm}$ was measured using a microphotometer (Photon Technology Intl, Princeton, NJ, USA). Background fluorescence was automatically subtracted and determined by removing the cell from the field before the experiments were started. The fluorescence acquisition rate was $0.5 \mathrm{~s}$. Intracellular $\mathrm{Ca}^{2+}$ concentration $\left(\left[\mathrm{Ca}^{2+}\right]_{\mathrm{i}}\right)$ was calculated according to the formula of Grynkiewicz et al. (1985). The $K_{\mathrm{d}}$ of Fura-2-AM was assumed to be $224 \mathrm{nM}$. The mean 340:380 fluorescence ratios $R_{\max }$ and $R_{\min }$ were obtained as previously reported (Grynkiewicz et al. 1985). Recordings were stored in a microcomputer and evaluated using a data acquisition and analysis software (Felix, version 1.21, Photon Technology Intl).

To evaluate the effect of the androgens on the $\left[\mathrm{Ca}^{2+}\right]_{\mathrm{i}}$, single myocytes were stimulated with $60 \mathrm{mM} \mathrm{KCl}$ (equimolar) to raise $\left[\mathrm{Ca}^{2+}\right]_{i}$, and this response was considered the control. Afterward, the cells were perfused with KHS for $15 \mathrm{~min}$. Immediately, the cells were incubated for $5 \mathrm{~min}$ with noncumulative concentrations of each androgen $(1,10,100$, and $320 \mathrm{nM})$, dissolved in absolute ethanol $(0.1 \% \mathrm{v} / \mathrm{v})$, and stimulated again with $60 \mathrm{mM} \mathrm{KCl}$ for each concentration. Finally, cells were washed with KHS and a last $60 \mathrm{mM} \mathrm{KCl}$ stimulus was done to evaluate their viability. We verified that ethanol, the vehicle for androgen administration, did not modify the response to $\mathrm{KCl}$. The effect of androgens was compared with the control response.

\section{Statistical analysis}

In the tension studies, all data in text and figures are expressed as a percentage of inhibition to the contraction induced by different agents $(\mathrm{KCl}, \mathrm{CCh}$, or OVA) and evaluated by comparing the amplitude of the contraction before (control 100\%) and 15 min after the addition of each androgen concentration. Bronchospasm was expressed as changes in $\mathrm{R}_{\mathrm{L}}$ (\% increase). Each experiment was carried out in individual guinea pigs $(n=6$, where $n=1$ represents one guinea pig). The non-paired Student's $t$-test was used to compare the response between two groups. The comparison between treatments and the control was done by one-way ANOVA followed by Dunnett's multiple comparison test. In the experiments with single cells, each experiment was carried out in individual cells ( $n \geq 3$ cells), a paired Student's $t$-test was used for comparison. To compare $\mathrm{IC}_{50}, \mathrm{ED}_{50}$, and $E_{\text {max }}$ between groups, a one-way ANOVA followed by Tukey's multiple comparisons test was used. Significance was accepted at $P<0.05$. Data presented in the text and figures are mean \pm s.E.M.

\section{Drugs and chemicals}

With exception of sodium pentobarbital (Anestesal; Pfizer, Mexico City, México), the remaining compounds were purchased from Sigma and included the following: TES (17 $\beta$ hydroxy-4-andosten-3-one), $5 \alpha$-DHT (17 $\beta$-hydroxy- $5 \alpha$ androstan-3-one), $5 \beta$-DHT (17 $\beta$-hydroxy- $5 \beta$-androstan-3one), carbachol chloride, BK, OVA, aluminum hydroxide, and L-NAME. The androgens were separately prepared as stock solutions in absolute ethanol and then diluted in the same solvent to the concentrations needed for each experiment; $10 \mu \mathrm{l}$ aliquots were added to the $10 \mathrm{ml}$ bath chambers, which never exceeded $0.5 \% \mathrm{v} / \mathrm{v}$ of vehicle, and the remaining drugs were dissolved in distilled water. BK was kept in the dark until use in order to avoid light-induced degradation.

\section{Results}

\section{Preventive effects of androgens against bronchospasm}

Figure $1 \mathrm{~A}$ shows the time-course of change in $R_{L}$ after challenge with OVA in the sensitized guinea pigs. After 4 min of the challenge, an elevation of basal $\mathrm{R}_{\mathrm{L}}$ value to $3.80 \pm 0.54 \mathrm{~cm} \mathrm{H}_{2} \mathrm{O} / \mathrm{ml}$ per s ( $n=6$ animals) was observed as the maximal peak of bronchospasm (fast response (FR)), 12 min later this acute response ended but the basal $\mathrm{R}_{\mathrm{L}}$ value was not restored for more than $30 \mathrm{~min}$ (delayed response (DR)). The FR was delayed ( $2 \mathrm{~min})$ when each androgen was given intravenously and decreased (19-92\%) in a dose-dependent manner. Furthermore, all androgens diminished (25-100\%) the DR, which was completely abolished at the highest dose tested (Fig. 1A). Figure 2B shows the percentages of prevention of the FR induced by each androgen; the order of potency was $5 \beta$-DHT $>$ TES $>5 \alpha$-DHT. The same dose-volume of the androgen vehicle $(40 \mu \mathrm{l}$ DMSO) did not change the

Published by Bioscientifica Ltd 
A

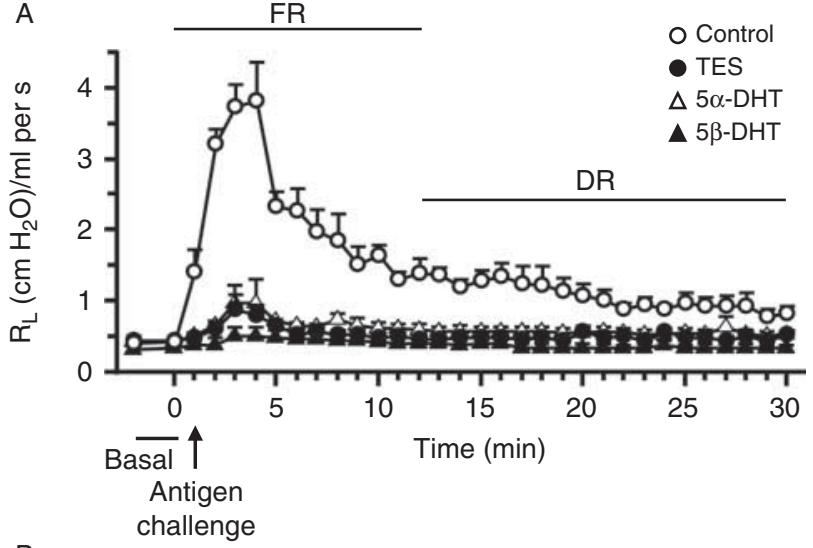

B

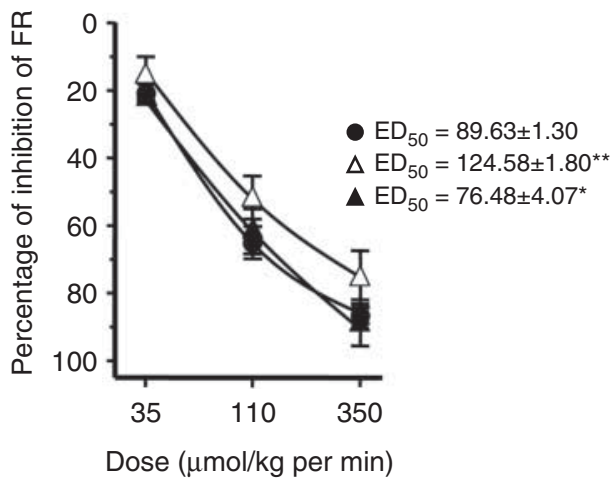

Figure 1

Lung resistance $\left(R_{L}\right)$ increased in response to antigen challenge in sensitized guinea pigs. (A) The fast response (FR) and delayed response (DR) of bronchospasm (control) were prevented by i.v. bolus injection of testosterone (TES), $5 \alpha$, or $5 \beta$-dihydrotestosterone (DHT) at $350 \mu \mathrm{mol} / \mathrm{kg}$ per min administrated $15 \mathrm{~min}$ before the antigen challenge. (B) Dose-response curves to androgens of $R_{L}$ after 4 min of antigen challenge-induced bronchospasm ( $F R$, acute phase of bronchospasm). Differences were found in the effective dose $50\left(E D_{50}\right)$ of TES and its metabolites $\left({ }^{*} P<0.05\right.$ and $* * P<0.0001$ ). Each value represents the mean \pm s.E.M. from six animals.

$R_{L}$ value after the antigen challenge. We observed that the bronchospasm prevention by androgens was not accompanied by significant changes in blood pressure and heart rate in any case (data not shown).

\section{Androgen effect on ASM contraction}

The three androgens tested were found to relax the contraction induced by contractile agents $(\mathrm{KCl}, \mathrm{CCh}$, and OVA) in a concentration-dependent manner (Fig. 2). No significant differences $(P>0.05)$ were found in the relaxation responses and potency elicited by androgens in non-sensitized and sensitized animals, vehicle $(P>0.05)$ did not significantly change the tone of the contraction elicited by different agents. Clearly, the analysis of these curves (Fig. 2) indicated that the relaxant potency $\left(\mathrm{IC}_{50}\right)$ of
$5 \beta$-DHT on $\mathrm{KCl}$-induced contraction is significantly greater $(P<0.01), 0.75$ times more potent, than that of TES, and 0.58 times more potent than that of $5 \alpha$-DHT. However, TES relaxes CCh- and OVA-induced contraction more potently than $5 \alpha$-DHT and $5 \beta$-DHT $(P<0.01)$, which were equipotent. The order of potency was i) for $\mathrm{KCl}$ induced contraction, $5 \beta$-DHT $>5 \alpha$-DHT $>$ TES and ii) for CCh- and OVA-induced contraction, TES $>5 \alpha$-DHT $\geq 5 \beta$ DHT. Regarding the relaxant efficacy $\left(E_{\max }\right)$, the same efficacy was observed for $5 \beta$-DHT and TES on KCl- and CCh-induced contraction where $5 \alpha$-DHT showed the least efficacy. Nevertheless, TES and $5 \alpha$-DHT had equivalent efficacy for relaxing the OVA-induced contraction, but $5 \beta$ DHT was less efficient. All androgens were capable of abolishing completely the tone of the contractions elicited by different contractile agents (100\% inhibition); notably, the different efficacies were obtained at the highest concentration tested $(200 \mu \mathrm{M})$ where the androgens diminished the basal tone ( $>100 \%$ of inhibition; below baseline), see concentration-response curves (Fig. 2).

In this study, the effects of presence or absence of epithelium were evaluated functionally in all experiments. Figure 3A shows that the presence of epithelium in the tracheal rings was confirmed when BK elicited a loss at the basal tone, and the absence of epithelium (rubbed preparations) was corroborated when $\mathrm{BK}$ increased the basal tone ( $\geq 0.3 \mathrm{~g}$ ). The relaxing effect of all androgens on $\mathrm{KCl}$ - or CChinduced contraction was not prevented when epithelium was removed. On the contrary, they had a greater relaxation $(P<0.0001)$ in preparations without epithelium, which is represented by their different $\mathrm{IC}_{50}$ values (Fig. 3B). Likewise, the relaxing effect of androgens was studied in the absence and presence of the NOS-inhibitor, L-NAME. This drug did not change the relaxing effect of androgens (Fig. 3C).

To explore the probable participation of $\mathrm{K}^{+}$channels in androgen-induced relaxation, we observed that pre-treatment with 1,10 , or $30 \mathrm{mM}$ TEA did not modify the concentration-response curves to androgens of the CCh-induced contraction (Fig. 4).

\section{$\left[\mathrm{Ca}^{2+}\right]_{i}$ measurements in single ASM cell}

Tracheal myocytes stimulated with $60 \mathrm{mM} \mathrm{KCl}$ produced an increment of $\left[\mathrm{Ca}^{2+}\right]_{\mathrm{i}}(165-199 \mathrm{nM})$, which was reproducible after several $\mathrm{KCl}$ stimuli (control response, Fig. 5A). The increment of $\left[\mathrm{Ca}^{2+}\right]_{\mathrm{i}}$ induced by $\mathrm{KCl}$ was significantly diminished $(P<0.05)$ in a concentration-dependent manner, when the cells were pre-incubated with TES or $5 \beta$-DHT (Fig. 5B and D). The results for $5 \alpha$-DHT did not significantly differ from those for controls at any concentrations tested

Published by Bioscientifica Ltd 

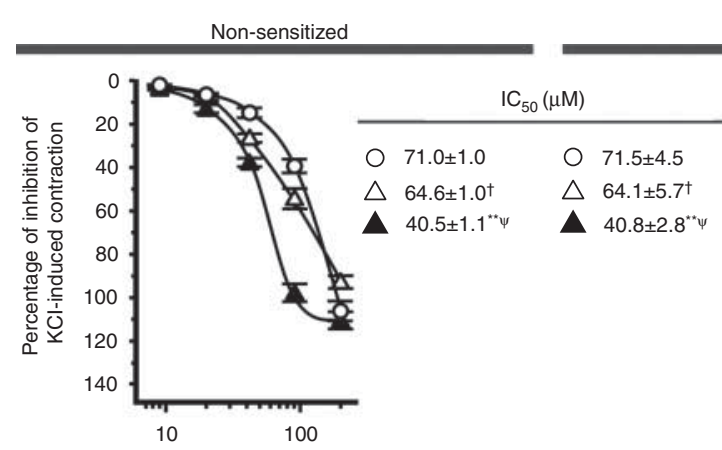

Sensitized
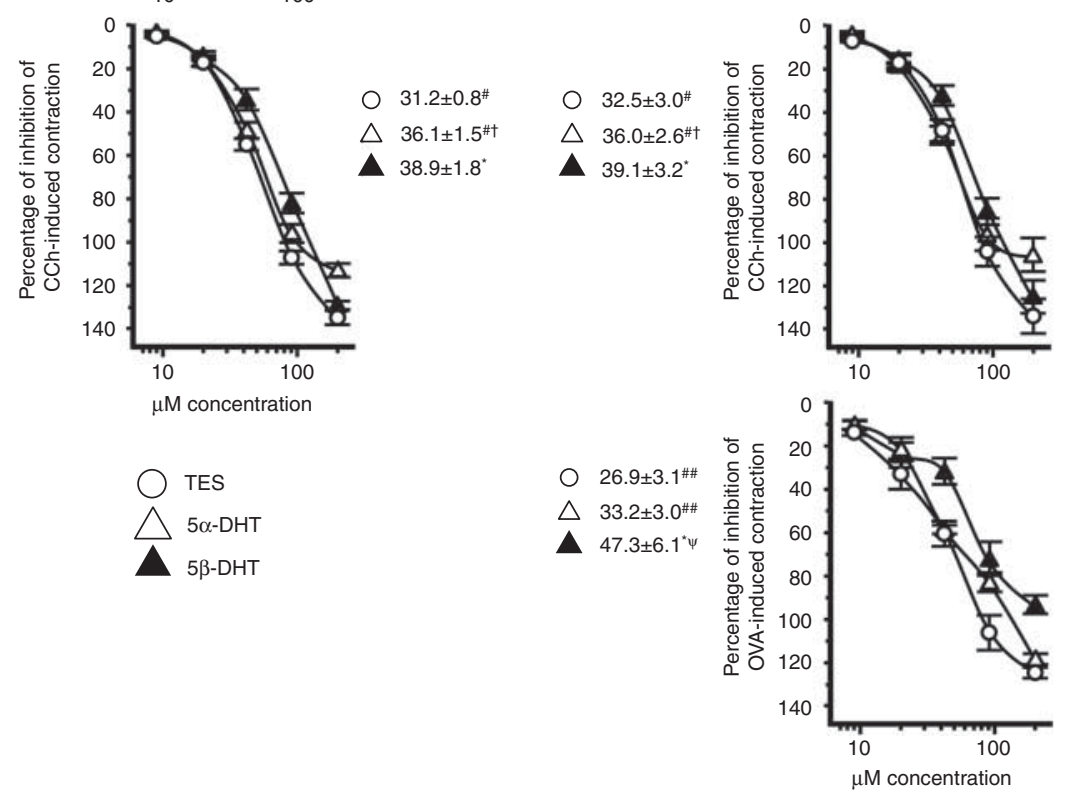

Figure 2

Concentration-response curves to androgens for different contractions in isolated tracheal smooth muscle. Androgen-induced relaxation in non-sensitized and sensitized guinea pigs did not differ significantly $(P>0.05)$. The inhibitory concentration 50 values $\left(I_{50}\right)$ indicate that testosterone (TES) and $5 \alpha$-DHT were significantly more potent for relaxing carbachol (CCh)-induced contraction ( $\left.{ }^{\#} P<0.00001\right)$ and ovalbumin (OVA)induced contraction $\left({ }^{\# \#} P<0.00001\right)$ than for relaxing the contraction

(P>0.05), with an $E_{\max }$ value of $36.66 \pm 12.49 \%$ for reduction of $\mathrm{KCl}$-induced $\left[\mathrm{Ca}^{2+}\right]_{\mathrm{i}}$ increment and consequently, its $\mathrm{IC}_{50}$ was not calculated (Fig. 5C). The $\mathrm{IC}_{50}$ for TES was $21.90 \pm 5.94 \mathrm{nM}$ and for $5 \beta$-DHT was $6.06 \pm 3.90 \mathrm{nM}$. Notably, $5 \beta$-DHT was 2.61 times more potent than TES. The vehicle used to deliver the androgens did not significantly affect $(P>0.05)$ the $\mathrm{KCl}$-induced $\left[\mathrm{Ca}^{2+}\right]_{\mathrm{i}}$ increment.

\section{Discussion}

Relaxation induced by TES and its five-reduced metabolites was examined in the present study. This is the first time, to our knowledge, that the relaxation induced by these androgens has been tested in an animal model of asthma.

induced by $\mathrm{KCl}$, while $5 \beta$-DHT was significantly more potent for relaxing $\mathrm{KCl}$-induced contraction $(P<0.01)$ but no differences were found in its potency for relaxing the three contractions $(P>0.05)$. The $I C_{50}$ of each androgen was significantly different: TES vs $5 \alpha$-DHT $\left({ }^{\dagger} P<0.01\right)$; TES vs $5 \beta$-DHT $\left({ }^{*} P<0.01\right.$ and $\left.* * P<0.00001\right)$; and $5 \alpha$-DHT vs $5 \beta-\mathrm{DHT}\left({ }^{\Psi} P<0.01\right)$. Each symbol in the curves represents the mean \pm s.E.M. of six independent experiments.

Our study reveals that androgen-induced relaxation in vitro is active in vivo due to the acute prevention of the antigeninduced bronchospasm.

\section{Bronchospasm prevention by androgens}

As guinea pig models can provide some of the essential features of human asthma, we have established that the androgen-induced relaxation of isolated trachea of guinea pigs and rabbits (Kouloumenta et al. 2006, Bordallo et al. 2008) is consistent with the results of the present in vivo studies, which is, to our knowledge, the first evidence of the bronchodilating effect elicited by androgens in an in vivo model of allergic asthma. Androgens actually diminished 

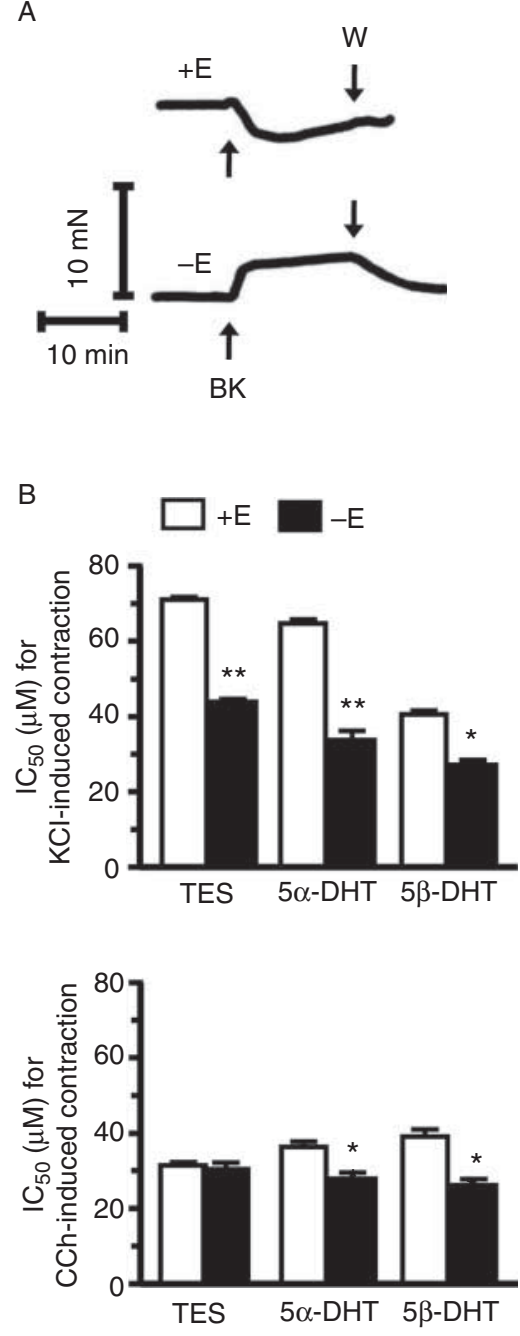
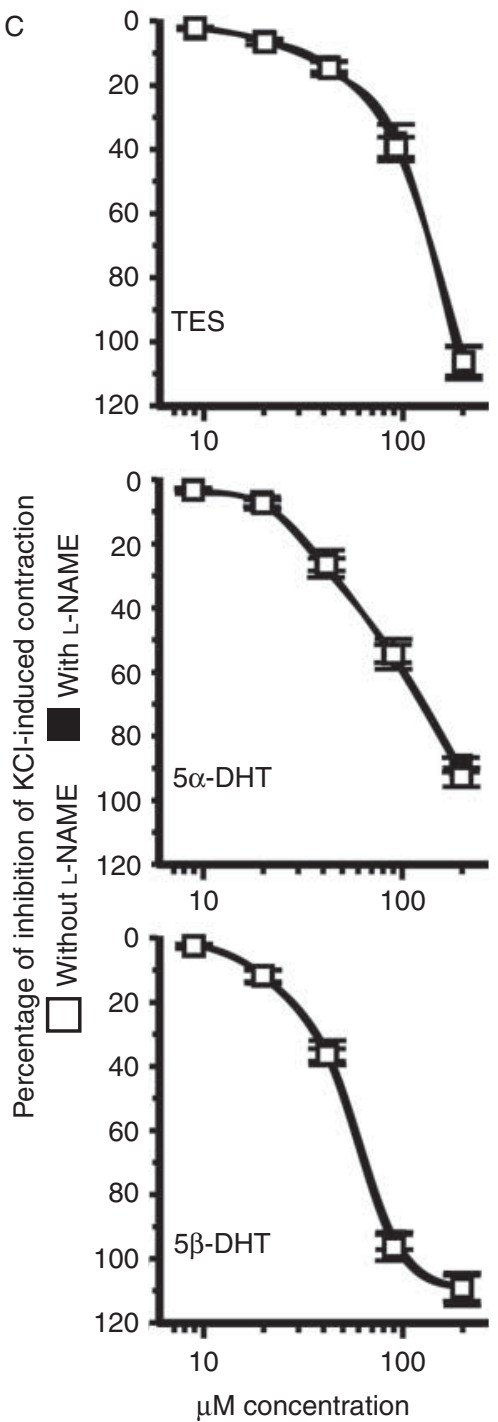

(B) Androgen-induced relaxation was increased, but not prevented, in $-\mathrm{E}$ preparations; significant differences in the $\mathrm{IC}_{50}$ value for each androgen were observed $(* P<0.0001$ and $* * P<0.000001)$, each bar represents the mean \pm s.E.M. $(n=6)$. (C) The nitric oxide synthase inhibitor (L-NAME, $10 \mu \mathrm{M})$ did not change the concentration-response curves of androgen-induced relaxation, $n=6 \pm$ s.E.M.

activity of androgens against a bronchospasm revealed the same order of potency as that observed in the in vitro experiments described below (5 $\beta$-DHT exhibited major potency than TES and $5 \alpha$-DHT). Therefore, the order of potency might mainly reside in its chemical structure.

\section{Androgens relaxing mechanism}

The magnitude of the relaxing effect of androgens in vitro was similar for tissues from non-sensitized and sensitized

Published by Bioscientifica Ltd. http://joe.endocrinology-journals.org DOI: 10.1530/JOE-14-0074
(C) 2014 Society for Endocrinology Printed in Great Britain 


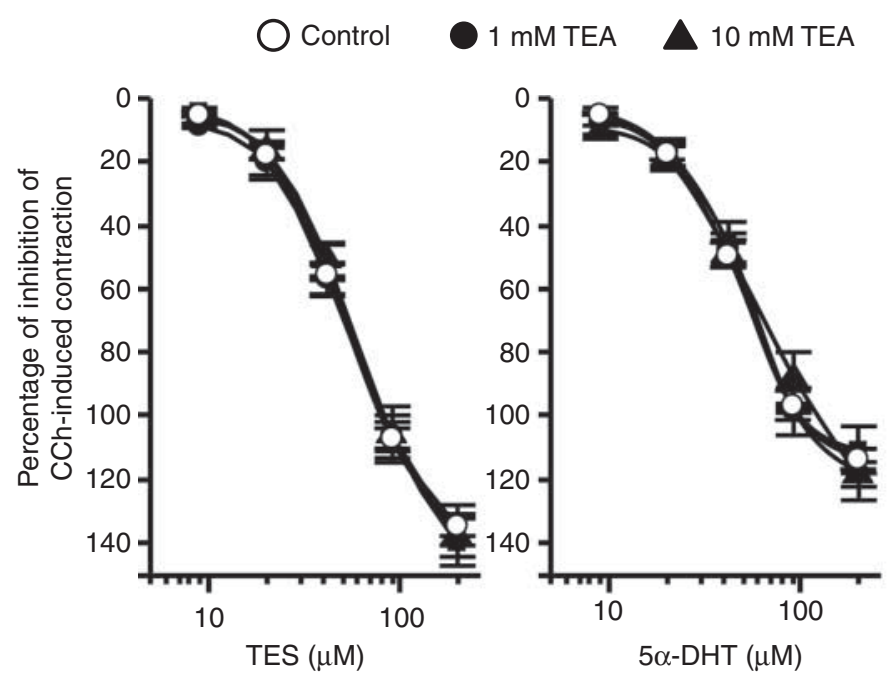

$30 \mathrm{mM}$ TEA

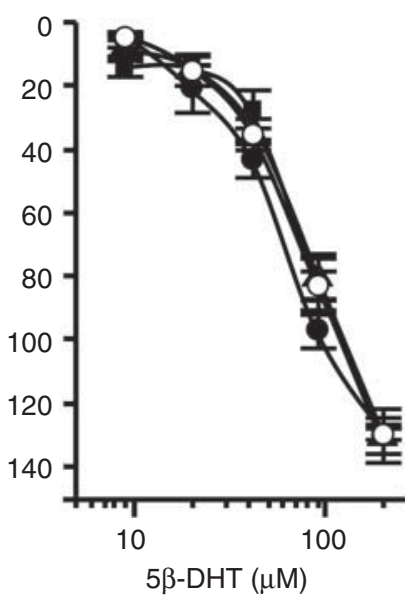

Figure 4

Blockade of $\mathrm{K}^{+}$channels in androgen-induced relaxation. Tetraethylammonium (TEA) at 1,10 , or $30 \mathrm{mM}$ did not modify ( $P>0.05$ vs control) the relaxing effect induced by testosterone (TES), $5 \alpha-\mathrm{DHT}$ and $5 \beta-\mathrm{DHT}$, on

animals, demonstrating that the pathological status might not be an important factor for the relaxing effect induced by androgens. The implication that androgens assayed induce relaxation of contractions induced by different contractile responses, including OVA-induced constriction in sensitized animals, deserves further consideration.

Notably, KCl-induced contraction was more sensitive to $5 \beta$-DHT than to TES or $5 \alpha$-DHT, implying a reduction in extracellular $\mathrm{Ca}^{2+}$ influx due to the blockade of the L-type voltage-operated $\mathrm{Ca}^{2+}$ channel (VOCC), strongly induced by $5 \beta$-DHT and moderately induced by $5 \alpha$-DHT and TES. This finding was confirmed by the fact that the $5 \beta$-reduced androgen was the most potent for diminishing $\mathrm{KCl}$ induced $\left[\mathrm{Ca}^{2+}\right]_{\mathrm{i}}$ increment in a single cell, in contrast to its $5 \alpha$ isomer which was weakly effective. Moreover, this important evidence categorically shows that androgens, indeed, are blocking the VOCC to diminish $\left[\mathrm{Ca}^{2+}\right]_{i}$ at nanomolar concentrations and might be even acting at plasmatic concentrations in adult men with TES ranges from 11 to $36 \mathrm{nmol} / 1$. Remarkably, the single cells required much lower concentrations of the androgen than the isolated tissue, due to the fact that it was directly applied to a single tracheal cell.

In agreement with our data, previous observations during functional studies had indicated that the relaxing effect elicited by $5 \alpha$-DHT (Bordallo et al. 2008) and DHEA (Espinoza et al. 2013) might directly inhibit $\mathrm{Ca}^{2+}$ entry, where the VOCCs are involved. Consistent with this view, recent electrophysiological studies, including our own, carbachol (CCh)-induced contraction in isolated guinea pig tracheal smooth muscle.

have demonstrated that androgens also induce relaxation in vascular and uterine smooth muscle by blocking VOCC (for review see Perusquía et al. (2005), Montaño et al. (2008) and Perusquía \& Stallone (2010)).

In contrast to $\mathrm{KCl}$-induced contraction, the $\mathrm{CCh}$ - and OVA-induced contraction may involve mechanisms other than activation of VOCCs. Therefore, this implies that androgens induced relaxation by more complex processes. It is well known that the CCh-induced contraction has two phases: a rapid phasic contraction and a tonic sustained contraction. In guinea pig ASM, the first one mainly involves $\mathrm{Ca}^{2+}$ released from the sarcoplasmic reticulum, VOCC and store operated $\mathrm{Ca}^{2+}$ entry (SOCE; Flores-Soto et al. 2013) and the second probably involves VOCC, SOCE, and receptor-operated $\mathrm{Ca}^{2+}$ channels (ROCC). The outstanding ability to relax this kind of contraction of TES and $5 \alpha$-DHT indicates that in addition to the blocking action on VOCC, these may be better blockers of the SOCE and ROCC than 5 $\beta$-DHT. This evidence is consistent with the slight diminution on KCl-induced $\left[\mathrm{Ca}^{2+}\right]_{\mathrm{i}}$ increment, particularly elicited by $5 \alpha$ DHT and to a lesser extent by TES. In conclusion, our results indicate that the mechanisms of androgen-induced relaxation in ASM are at least partially mediated via blockade of SOCE and ROCC in addition to the blocking action on VOCC. Recently, we have found that DHEA elicited a complete relaxation of OVA-induced ASM contraction in guinea pig (Espinoza et al. 2013). Because androgens tested in the present work also relax the

Published by Bioscientifica Ltd 


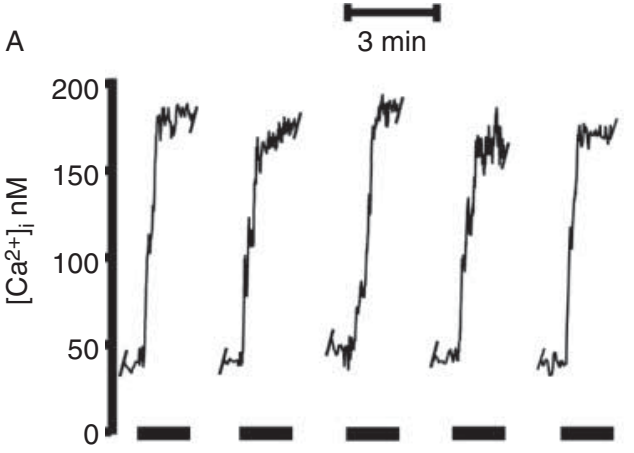

B

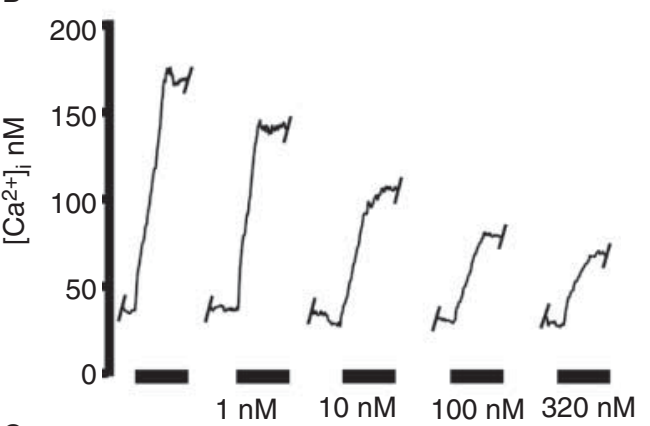

C
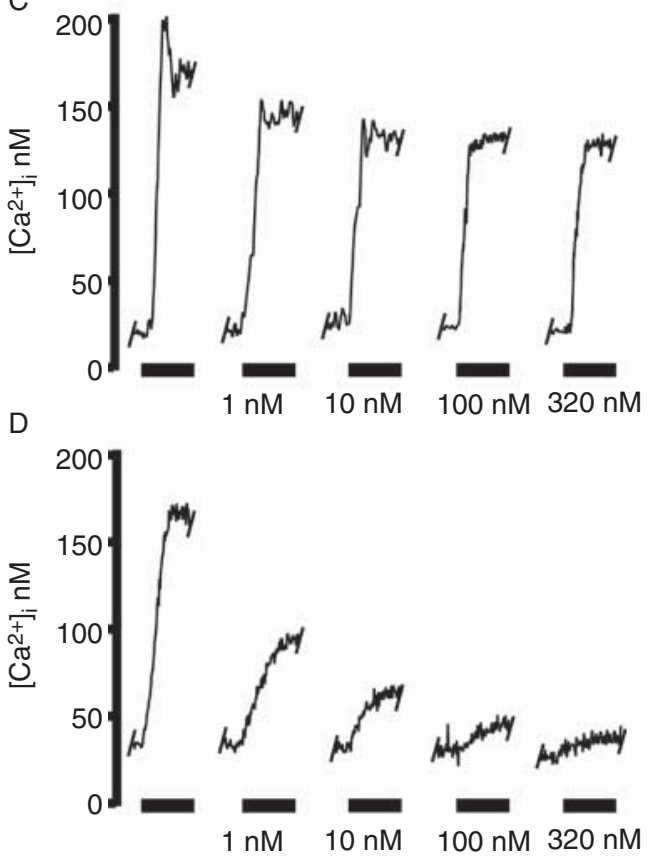

Figure 5

Representative recordings of androgen responses for $\mathrm{KCl}$-induced $\left[\mathrm{Ca}^{2+}\right]_{i}$ increment in single cell at nanomolar (nM) concentrations. (A) Cells stimulated with $60 \mathrm{mM} \mathrm{KCl}$ (short black lines) produced an increment of $\left[\mathrm{Ca}^{2+}\right]_{\mathrm{i}}$ (control response). (B) The increment of $\left[\mathrm{Ca}^{2+}\right]_{\mathrm{i}}$ induced by $\mathrm{KCl}$ was significantly diminished $(P<0.05)$ by testosterone in a concentrationdependent manner. (C) The effect of $5 \alpha$-dihydrotestosterone ( $5 \alpha$-DHT) on $\mathrm{KCl}$-induced $\left[\mathrm{Ca}^{2+}\right]_{i}$ increment was not significant $(P>0.05)$ and did not differ significantly at any concentrations tested $(P>0.05)$. (D) Notably, $5 \beta$-DHT concentration-dependently induced the most potent diminution of $\mathrm{KCl}$-induced $\left[\mathrm{Ca}^{2+}\right]_{\mathrm{i}}$ increment $(P<0.05)$.
OVA-induced contraction, they might be also acting in a similar way to that previously discussed for CCh. Nevertheless, it is important to highlight that each androgen may have a preferential site of action for inducing relaxation.

Regarding the role that the tracheal epithelium may play in androgen-induced relaxation, it has been reported that the absence of epithelium in isolated rabbit trachea 'attenuated' but did not abolish relaxing effect of TES, which indicated a partially epithelium-dependent mechanism (Kouloumenta et al. 2006). In contrast, another study demonstrated an epithelium-independent mechanism for TES and its metabolites in guinea pig trachea (Bordallo et al. 2008). These two studies have conflicting findings; in both works the authors did not show data verifying that the epithelium had been removed. We have observed that the tracheal epithelial layer in guinea pigs is not adequately removed when a cottontipped applicator is gently used as previously reported (Bordallo et al. 2008); thus, in our study the preparations were vigorously rubbed with a dental drill bur with cylinder round end to eliminate completely the epithelium, which was always pharmacologically confirmed. Our data clarified the role of epithelium under highly controlled conditions, i) androgen-induced relaxation was not prevented when the epithelium was removed and ii) epithelium removal caused a greater relaxing effect in response to androgen. These findings indicate that androgens act directly on the ASM cells, and that the mucosa, including epithelium, might be limiting the androgen diffusion to the ASM and/or that the epithelium-derived contracting factors might counteract the relaxing effect induced by androgens. In addition, the fact that L-NAME did not prevent the relaxing effect of androgens leads us to rule out the involvement of NO in the androgen action in guinea pig. These data disagree with the suggestion that TES induces relaxation in rabbit trachea via an epithelium-mediated mechanism (Kouloumenta et al. 2006); in view of that, the epithelial contribution may be species dependent.

Admittedly, androgens may open $\mathrm{K}^{+}$channels in ASM. TEA (1-30 mM) did not inhibit androgen-induced relaxation. Because TEA blocks $\mathrm{K}_{\mathrm{v}}$ and $\mathrm{BK}_{\mathrm{Ca}}$, which are the most important $\mathrm{K}^{+}$channels in ASM (Montaño et al. 2011), it can be concluded that they do not participate in the androgen-induced relaxation. In addition, the possibility that the $\beta_{2}$-adrenoceptors are involved in the relaxation to $5 \alpha$-DHT or DHEA (Bordallo et al. 2008, Espinoza et al. 2013), as well as the polyamine synthesis in the relaxation induced by $5 \alpha$-DHT (Bordallo et al. 2008), has been eliminated.

Published by Bioscientifica Ltd. 


\section{Chemical structure-brochorelaxing activity relationship of androgens}

The potency of each androgen for relaxing the different contractions might be dependent on its structural conformation and preferential site of action. Thus, the structural conformation of TES ( $\Delta 4$-3ceto configuration) and $5 \alpha$-DHT ( $5 \alpha$-configuration) might display a preference for inactivating ROCC and SOCE. In contrast, $5 \beta$-DHT (5 5 -configuration) acquires a dramatic bend in its A-ring, which might result in preferential interaction with the VOCC, acting predominantly as a L-type $\mathrm{Ca}^{2+}$ blocker. Remarkably, it was clear that $5 \beta$-DHT is more efficacious at preventing contraction by inducing strong ASM relaxation, particularly on $\mathrm{KCl}$-induced contraction, to diminish $\mathrm{KCl}$-induced $\left[\mathrm{Ca}^{2+}\right]_{\mathrm{i}}$ increment and to prevent bronchospasm. In this sense, the A-ring reduction in TES at the $5 \beta$ position (5 $\beta$-DHT) gives an optimal activity for preventing bronchospasm. This chemical structure-relaxing activity relationship is consistent with our previous studies, where progesterone ( $\Delta 4$-3ceto configurated) and its 5 -reduced metabolites ( $5 \alpha$-progestin and $5 \beta$-progestin) have the same chemical structure-relaxing activity relationship in isolated guinea pig trachea. $5 \beta$-Progestin exhibited more potent relaxation than progesterone, and $5 \alpha$-progestin displayed the lowest potency (Perusquía et al. 1997). Likewise, we have reported that $5 \alpha$-DHT exhibits a lower efficacy and/or potency than TES for inducing vascular (Perusquía et al. 2007, 2012, Perusquía \& Stallone 2010) and uterine (Perusquía 2001, Perusquía et al. 2005) relaxation, but $5 \beta$ DHT is markedly more potent than TES. Taken together, our findings indicate that the mechanism of action of androgeninduced relaxation are dependent on different molecular structures and cannot be generalized and/or established when only one type of androgen has been studied.

\section{Physiological and clinical relevance}

In men, severity of asthma is relatively stable from puberty until later in life (e.g. $<50$ years), when decreasing serum TES levels may contribute to increasing the severity of this illness (Zannolli \& Morgese 1997, Canguven \& Albayrak 2011). As androgens can modulate pulmonary inflammatory processes (da Silva 1999, Yu et al. 1999, Kasperska-Zajac 2010, Koziol-White et al. 2012) and ASM function by inducing bronchorelaxation (this study), these properties indicate that they are bronchobioactive drugs, and thereby may play a relevant role in the occurrence of asthma. It is important to take into account the fact that androgen metabolism has been shown in airways; for instance, in alveolar macrophages with conversion of androstenedione into TES and $5 \alpha$-DHT (Milewich et al. 1983) and perhaps into its $5 \beta$ isomer.

In this context, androgen deficiency may be considered at least partly accountable for asthma symptoms. This suggestion correlates well with an early clinical study. TES ( $10 \mathrm{mg} /$ day for 5 days) was found to improve symptoms in $88 \%$ of women suffering from premenstrual asthma (Wulfsohn et al. 1964). Female patients suffering from status asthmaticus found rapid, acute relief (within $20 \mathrm{~min}$ ) with a combined TES-gonadotropin injection $(12.5 \mathrm{mg}, 500 \mathrm{IU}$ respectively) (Wulfsohn et al. 1964). Although these limited data are from an old study, they do indicate that increased androgen levels may be beneficial in both males and females. Therefore, androgen replacement therapy after middle age to prevent or attenuate asthma symptoms may be considered in men. However, the virilizing effects of androgens, particularly of TES and $5 \alpha$-DHT in females, and their implication in the genesis of prostatic cancer in males are an obvious concern and a recognized limitation. Nevertheless, $5 \beta$-DHT is an excellent alternative for treating asthma in men and women due to its good action as antibronchospasmodic. Moreover, $5 \beta$-DHT possesses several qualities: it is a nonaromatizable androgen, thus without estrogenic effects, and has no affinity for the androgen receptor and is devoid of androgenic actions, theoretically without virilizing or, estrogenic effects, there is no possibility of induction of prostatic cancer.

\section{Declaration of interest}

The authors declare that there is no conflict of interest that could be perceived as prejudicing the impartiality of the research reported.

\section{Funding}

This research was supported by grants from the Programa de Apoyo a Proyectos de Investigación e Innovación Tecnológica/Dirección General de Asuntos del Personal Académico (grant number IN205511-3 to M P and part of grant number IN200613-3 to L M M).

\section{Acknowledgements}

The authors are grateful to Bettina Sommer for her English proof reading.

\section{References}

Almqvist C, Worm M \& Leynaert B 2008 Impact of gender on asthma in childhood and adolescence: a GA ${ }^{2} \mathrm{LEN}$ review. Allergy 63 47-57. (doi:10.1111/j.1398-9995.2007.01524.x)

Becklake MR \& Kauffmann F 1999 Gender differences in airway behaviour over the human life span. Thorax 54 1119-1138. (doi:10.1136/thx. 54.12.1119) http://joe.endocrinology-journals.org DOI: 10.1530/JOE-14-0074
C 2014 Society for Endocrinology Printed in Great Britain
Published by Bioscientifica Ltd 
Bonner JR 1984 The epidemiology and natural history of asthma. Clinics in Chest Medicine 5 557-565.

Bordallo J, de Boto MJ, Meana C, Velasco L, Bordallo C, Suárez L, Cantabrana B \& Sánchez M 2008 Modulatory role of endogenous androgens on airway smooth muscle tone in isolated guinea-pig and bovine trachea; involvement of $\beta_{2}$-adrenoceptors, the polyamine system and external calcium. European Journal of Pharmacology $\mathbf{6 0 1}$ 154-162. (doi:10.1016/j.ejphar.2008.10.039)

Bramley AM, Samhoun MN \& Piper PJ 1990 The role of the epithelium in modulating the responses of guinea-pig trachea induced by bradykinin in vitro. British Journal of Pharmacology 99 762-766. (doi:10.1111/j.14765381.1990.tb13003.x)

Campos-Bedolla P, Vargas MH, Calixto E, Segura P, Mendoza-Patino N, Figueroa A, Flores-Soto E, Barajas-López C \& Montaño LM 2006 $\alpha$-methyl-5-HT, a 5- $\mathrm{HT}_{2}$ receptor agonist, stimulates $\beta_{2}$-adrenoceptors in guinea pig airway smooth muscle. Pharmacological Research 54 468-473. (doi:10.1016/j.phrs.2006.09.006)

Canguven O \& Albayrak S 2011 Do low testosterone levels contribute to the pathogenesis of asthma? Medical Hypotheses 76 585-588. (doi:10.1016/ j.mehy.2011.01.006)

Chen W, Mempel M, Schober W, Behrendt H \& Ring J 2008 Gender difference, sex hormones, and immediate type hypersensitivity reactions. Allergy 63 1418-1427. (doi:10.1111/j.1398-9995.2008.01880.x)

Corrales JJ, Almeida M, Burgo R, Mories MT, Miralles JM \& Orfao A 2006 Androgen-replacement therapy depresses the ex vivo production of inflammatory cytokines by circulating antigen-presenting cells in aging type-2 diabetic men with partial androgen deficiency. Journal of Endocrinology 189 595-604. (doi:10.1677/joe.1.06779)

Cutolo M 1997 Do sex hormones modulate the synovial macrophages in rheumatoid arthritis? Annals of the Rheumatic Diseases 56 281-284. (doi:10.1136/ard.56.5.281)

Dalal M, Kim S \& Voskuhl RR 1997 Testosterone therapy ameliorates experimental autoimmune encephalomyelitis and induces a T helper 2 bias in the autoantigen-specific T lymphocyte response. Journal of Immunology 159 3-6.

Espinoza J, Montaño LM \& Perusquía M 2013 Nongenomic bronchodilating action elicited by dehydroepiandrosterone (DHEA) in a guinea pig asthma model. Journal of Steroid Biochemistry and Molecular Biology 138 174-182. (doi:10.1016/j.jsbmb.2013.05.009)

Flores-Soto E, Reyes-García J, Sommer B \& Montaño LM 2013 Sarcoplasmic reticulum $\mathrm{Ca}^{2+}$ refilling is determined by L-type $\mathrm{Ca}^{2+}$ and store operated $\mathrm{Ca}^{2+}$ channels in guinea pig airway smooth muscle. European Journal of Pharmacology 721 21-28. (doi:10.1016/j.ejphar.2013.09.060)

Grynkiewicz G, Poenie M \& Tsien RY 1985 A new generation of $\mathrm{Ca}^{2+}$ indicators with greatly improved fluorescence properties. Journal of Biological Chemistry $2603440-3450$.

Haggerty CL, Ness RB, Kelsey S \& Waterer GW 2003 The impact of estrogen and progesterone on asthma. Annals of Allergy, Asthma \& Immunology 90 284-291. (doi:10.1016/S1081-1206(10)61794-2)

Jeon YH, Yang HJ \& Pyun BY 2009 Lung function in Korean adolescent girls: in association with obesity and the menstrual cycle. Journal of Korean Medical Science 24 20-25. (doi:10.3346/jkms.2009.24.1.20)

Kasperska-Zajac A 2010 Asthma and dehydroepiandrosterone (DHEA): facts and hypotheses. Inflammation 33 320-324. (doi:10.1007/s10753-010-9188-1)

Kjellman B \& Gustafsson PM 2000 Asthma from childhood to adulthood: asthma severity, allergies, sensitization, living conditions, gender influence and social consequences. Respiratory Medicine 94 454-465. (doi:10.1053/rmed.1999.0764)

Kouloumenta V, Hatziefthimiou A, Paraskeva E, Gourgoulianis K \& Molyvdas PA 2006 Non-genomic effect of testosterone on airway smooth muscle. British Journal of Pharmacology 149 1083-1091. (doi:10.1038/sj.bjp.0706936)

Koziol-White CJ, Goncharova EA, Cao G, Johnson M, Krymskaya VP \& Panettieri RA 2012 DHEA-S inhibits human neutrophil and human airway smooth muscle migration. Biochimica et Biophysica Acta 1822 1638-1642. (doi:10.1016/j.bbadis.2012.06.012)
Malkin CJ, Pugh PJ, Jones RD, Kapoor D, Channer KS \& Jones TH 2004 The effect of testosterone replacement on endogenous inflammatory cytokines and lipid profiles in hypogonadal men. Journal of Clinical Endocrinology and Metabolism 89 3313-3318. (doi:10.1210/ jc.2003-031069)

de Marco R, Locatelli F, Sunyer J \& Burney P 2000 Differences in incidence of reported asthma related to age in men and women. A retrospective analysis of the data of the European Respiratory Health Survey. American Journal of Respiratory and Critical Care Medicine 162 68-74. (doi:10.1164/ajrccm.162.1.9907008)

Melgert BN, Ray A, Hylkema MN, Timens W \& Postma DS 2007 Are there reasons why adult asthma is more common in females? Current Allergy and Asthma Reports 7 143-150. (doi:10.1007/s11882-007-0012-4)

Milewich L, Lipscomb MF, Whisenant MG \& MacDonald PC 1983 Conversion of androstenedione to testosterone and other androgens in guinea-pig alveolar macrophages. Journal of Steroid Biochemistry 19 1611-1615. (doi:10.1016/0022-4731(83)90378-3)

Montaño LM, Calixto E, Figueroa A, Flores-Soto E, Carbajal V \& Perusquía M 2008 Relaxation of androgens on rat thoracic aorta: testosterone concentration dependent agonist/antagonist L-type $\mathrm{Ca}^{2+}$ channel activity, and 5 $\beta$-dihydrotestosterone restricted to L-type $\mathrm{Ca}^{2+}$ channel blockade. Endocrinology 149 2517-2526. (doi:10.1210/en.2007-1288)

Montaño LM, Cruz-Valderrama JE, Figueroa A, Flores-Soto E, GarcíaHernández LM, Carbajal V, Segura P, Méndez C, Díaz V \& Barajas-López C 2011 Characterization of P2Y receptors mediating ATP induced relaxation in guinea pig airway smooth muscle: involvement of prostaglandins and $\mathrm{K}^{+}$channels. Pflügers Archiv: European Journal of Physiology 462 573-585. (doi:10.1007/s00424-011-0997-3)

Mutius EV \& Martínez FD 1999 Epidemiology of childhood asthma. In Pediatric Asthma: Lung Biology in Health and Disease, pp 1-39. Eds S Murphy \& W Kelly. New York: Marcel Dekker, Inc.

Ninan TK \& Russell G 1992 Respiratory symptoms and atopy in Aberdeen schoolchildren: evidence from two surveys 25 years apart. BMJ $\mathbf{3 0 4}$ 873-875. (doi:10.1136/bmj.304.6831.873)

Osman M 2003 Therapeutic implications of sex differences in asthma and atopy. Archives of Disease in Childhood 88 587-590. (doi:10.1136/ adc.88.7.587)

Paoletti P, Carrozzi L, Viegi G, Modena P, Ballerin L, Di Pede F, Grado L, Baldacci S, Pedreschi M \& Vellutini M 1995 Distribution of bronchial responsiveness in a general population: effect of sex, age, smoking, and level of pulmonary function. American Journal of Respiratory and Critical Care Medicine 151 1770-1777. (doi:10.1164/ajrccm.151.6.7767519)

Perusquía M 2001 Nongenomic action of steroids in myometrial contractility. Endocrine 15 63-72. (doi:10.1385/ENDO:15:1:063)

Perusquía M \& Stallone JN 2010 Do androgens play a beneficial role in the regulation of vascular tone? Nongenomic vascular effects of testosterone metabolites American Journal of Physiology. Heart and Circulatory Physiology 298 H1301-H1307. (doi:10.1152/ajpheart.00753.2009)

Perusquía M, Hernández R, Montaño LM, Villalón CM \& Campos MG 1997 Inhibitory effect of sex steroids on guinea-pig airway smooth muscle contractions. Comparative Biochemistry and Physiology. Part C, Pharmacology, Toxicology \& Endocrinology 118 5-10. (doi:10.1016/ S0742-8413(97)00029-7)

Perusquía M, Navarrete E, Jasso-Kamel J \& Montaño LM 2005 Androgens induce relaxation of contractile activity in pregnant human myometrium at term: a nongenomic action on L-type calcium channels. Biology of Reproduction 73 214-221. (doi:10.1095/biolreprod.104. 036954)

Perusquía M, Navarrete E, González L \& Villalón CM 2007 The modulatory role of androgens and progestins in the induction of vasorelaxation in human umbilical artery. Life Sciences 81 993-1002. (doi:10.1016/j.lfs. 2007.07.024)

Perusquía M, Espinoza J, Montaño LM \& Stallone JN 2012 Regional differences in the vasorelaxing effects of testosterone and its 5-reduced metabolites in the canine vasculature. Vascular Pharmacology 56 176-182. (doi:10.1016/j.vph.2012.01.008) 
Postma DS 2007 Gender differences in asthma development and progression. Gender Medicine 4 S133-S146. (doi:10.1016/ S1550-8579(07)80054-4)

Sears MR 1997 Epidemiology of childhood asthma. Lancet 350 1015-1020. (doi:10.1016/S0140-6736(97)01468-2)

da Silva JA 1999 Sex hormones and glucocorticoids: interactions with the immune system. Annals of the New Academy of Sciences 876 102-117. (doi:10.1111/j.1749-6632.1999.tb07628.x)

The International Study of Asthma and Allergies in Childhood (ISAAC) Steering Committee 1998 Worldwide variations in the prevalence of asthma symptoms: the International Study of Asthma and Allergies in Childhood (ISAAC). European Respiratory Journal 12 315-335. (doi:10.1183/09031936.98.12020315)

Ticconi C, Pietropolli A \& Piccione E 2013 Estrogen replacement therapy and asthma. Pulmonary Pharmacology \& Therapeutics 26 617-623. (doi:10.1016/j.pupt.2013.08.004)

Townsend EA, Thompson MA, Pabelick CM \& Prakash YS 2010 Rapid effects of estrogen on intracellular $\mathrm{Ca}^{2+}$ regulation in human airway smooth muscle. American Journal of Physiology. Lung Cellular and Molecular Physiology 298 L521-L530. (doi:10.1152/ajplung.00287.2009)

Townsend EA, Miller VM \& Prakash YS 2012 Sex differences and sex steroids in lung health and disease. Endocrine Reviews 33 1-47. (doi:10.1210/ er.2010-0031)

Traish AM, Kang HP, Saad F \& Guay AT 2011 Dehydroepiandrosterone (DHEA) - a precursor steroid or an active hormone in human physiology. Journal of Sexual Medicine 8 2960-2982. (doi:10.1111/ j.1743-6109.2011.02523.x)

Wulfsohn NL, Politzer WM \& Henrico JS 1964 Testosterone therapy in bronchial asthma. South African Medical Journal 38 170-172.

Yu CK, Yang BC, Lei HY, Chen YC, Liu YH, Chen CC \& Liu CW 1999 Attenuation of house dust mite Dermatophagoides farinae-induced airway allergic responses in mice by dehydroepiandrosterone is correlated with down-regulation of TH2 response. Clinical and Experimental Allergy 29 414-422. (doi:10.1046/j.1365-2222.1999.00484.x)

Zannolli R \& Morgese G 1997 Does puberty interfere with asthma? Medical Hypotheses 48 27-32. (doi:10.1016/S0306-9877(97)90020-7)

Received in final form 7 April 2014

Accepted 24 April 2014

Accepted Preprint published online 29 April 2014 